\title{
Carbohydrate Hydrogels with Stabilized Phage Particles for Bacterial Biosensing: Bacterium Diffusion Studies
}

\author{
Victor M. Balcão • Sérgio V. P. Barreira • \\ Thiago M. Nunes • Marco V. Chaud • Matthieu Tubino • \\ Marta M. D. C. Vila
}

Received: 22 July 2013 / Accepted: 1 October 2013/

Published online: 23 October 2013

(C) Springer Science+Business Media New York 2013

\begin{abstract}
Bacteriophage particles have been reported as potentially useful in the development of diagnosis tools for pathogenic bacteria as they specifically recognize and lyse bacterial isolates thus confirming the presence of viable cells. One of the most representative microorganisms associated with health care services is the bacterium Pseudomonas aeruginosa, which alone is responsible for nearly $15 \%$ of all nosocomial infections. In this context, structural and functional stabilization of phage particles within biopolymeric hydrogels, aiming at producing cheap (chromogenic) bacterial biosensing devices, has been the goal of a previous research effort. For this, a detailed knowledge of the bacterial diffusion profile into the hydrogel core, where the phage particles lie, is of utmost importance. In the present research effort, the bacterial diffusion process into the biopolymeric hydrogel core was mathematically described and the theoretical simulations duly compared with experimental results, allowing determination of the effective diffusion coefficients of $P$. aeruginosa in the agar and calcium alginate hydrogels tested.
\end{abstract}

Keywords Structurally/functionally stabilized bacteriophage $\cdot$ Bacterial biosensing . Bacterial diffusion $\cdot$ Mathematical modeling $\cdot$ Carbohydrate hydrogels

This manuscript has been submitted for publication in Applied Biochemistry and Biotechnology. It is not to be reproduced or cited without the written permission from the authors.

V. M. Balcão $(\bowtie) \cdot$ T. M. Nunes $\cdot$ M. V. Chaud $\cdot$ M. M. D. C. Vila

Laboratory for the Development and Evaluation of Bioactive Substances, University of Sorocaba, Cidade Universitária, Rod. Raposo Tavares km 92.5, 18023-000 Sorocaba, São Paulo, Brazil

e-mail: vbalcao@ufp.edu.pt

V. M. Balcão · S. V. P. Barreira

Bioengineering and Biopharmaceutical Chemistry Research Group, University Fernando Pessoa, Rua Carlos da Maia no. 296, 4200-150 Porto, Portugal

V. M. Balcão

Institute for Biotechnology and Bioengineering (IBB), Centre for Biological Engineering, University of Minho, Campus de Gualtar, 4710-057 Braga, Portugal

M. Tubino

Institute of Chemistry, University of Campinas, 13083-970 Campinas, São Paulo, Brazil 


\section{Introduction}

Bacterial infections associated with health care services are widespread and represent major causes of morbidity and mortality [1-3]. Interest in Pseudomonas aeruginosa detection has emerged in response to the prevalence of this organism and its status as a clinically important, opportunistic pathogen that infects hosts with compromised immune systems $[4,5]$, which alone is responsible for ca. $15 \%$ of all nosocomial infections in Brazil [1, 6-9]. Bacterial migration is important in understanding many practical problems ranging from disease pathogenesis to the bioremediation of hazardous wastes in the environment $[10,11]$. The goal of the research effort entertained herein was to study the diffusion of the Gram negative $[4,12] P$. aeruginosa (a motile pathogenic bacteria) in continuum biopolymeric three-dimensional (3D) hydrogels, upon contact of a bacterial suspension with said hydrogels, and investigate the combined effects of hydrogel porosity and constrictivity factors on the process of bacteria diffusion into the hydrogel core. Systems such as the hydrogel matrix and the bacterial suspension, which are not in equilibrium, tend toward equilibrium according to the second law of thermodynamics, a phenomenon that occurs due to a difference in the chemical potential of a component between one region in space and another. There are many factors potentially responsible for a difference in chemical potential, viz. concentration, temperature, pressure differences, and differences in potential caused by external sources (such as gravity, magnetic forces, etc.). $P$. aeruginosa cells $(0.6 \times 1.5 \mu \mathrm{m})$ uses its single polar flagellum $(2 \mu \mathrm{m} \times 15 \mathrm{~nm}(\phi))$ that operates as a rear propulsion engine when swarming [13] and secretes a soluble biosurfactant (rhamnolipid) that changes the surface tension of the liquid film and is important for the swarming process [13]. This bacteria produces rhamnolipid in response to quorum sensing, and then this molecule extracts liquid from the hydrogel as well as decreases the surface tension of the liquid, which in turn eases liquid spreading and cell movement [13]. In the research effort described herein, the only driving force considered is a bacterial cell concentration gradient between the hydrogel and the bacterial suspension above it. In this way, we succeeded in quantifying bacterial diffusion into the core of (porous) biopolymeric (agar and calcium alginate) hydrogels, aiming at predicting the time needed to achieve biosensing and optimizing the design of the biosensing device. For this, balance equations were developed with appropriate boundary conditions that incorporate not only parameters based on hydrogel properties, such as porosity, constrictivity, and tortuosity, but also fundamental description of the microscopic motion of bacterial cells. Hydrogels are hydrophilic 3D polymeric networks that are either chemically crosslinked or physically entangled, with excellent water swelling capacities [14]. On a molecular level, water in a hydrogel is either bonded to polar hydrophilic groups as "bound water" or is filling the space between the network chains, pores or voids as "free water" [15-17]. As water acts as a plasticizer in a hydrophilic polymer network system, the swelling process of the hydrogel can be considered under rubbery state. Hydrogels are, therefore, predominantly composed of water, which fills the space between the hydrogel polymers. The average distance between distinct polymer strands is referred to as the hydrogel mesh size. An exact measurement of hydrogel mesh sizes is, however, difficult to achieve. Hydrogel pore sizes as obtained from the analysis of scanning electron microphotographs are prone to bias and artifacts that arise both from the need to stain hydrogel biopolymers with contrast-enhancing heavy metals and from structural collapse of the hydrogel promoted by electron beams during electron microscopy [18]. Inside a hydrogel mesh, the local microviscosity that a diffusing particle (or cell) encounters is typically close to that of water [17]. The research effort entertained herein is part of an effort to extend these 
results to bacterial migration/diffusion into (lytic) phage-containing chromogenic 3D hydrogels aiming at bacterial biosensing [5]. The hydrogels used in this research work were fixed to a 3D-matrix support, leaving a 2D-surface exposed to a (fixed volume of) bacterial suspension. The underlying rationale was that this one-surface limited interaction might increase the sensitivity of the bacterial biosensing system developed. Additionally, pore size-driven diffusion could also improve the overall selectivity of the biosensing device. In addition to the protection given to phage particles, the semi-solid nanoporous nature of the hydrogel matrix itself should facilitate the direct inoculation of the matrix with the biological (fluid) sample under study and its contact with the immobilized phage particles. To answer the question on to what extent does the morphology of the biopolymeric hydrogel matrix influences the random motility of the bacteria, experiments were designed so as to measure bacterial penetration in thin $3 \mathrm{D}$ hydrogels. The mathematical description/simulation entailed in the present research effort is of utmost importance if one intends to predict the time required by the chromogenic hydrogel kit to achieve ( $P$. aeruginosa) bacterial biosensing in a colorimetric fashion, evolving from reaction with (phage-released) intracytoplasmatic moieties.

\section{Materials and Methods}

Materials

\section{Biological Materials}

Bacteriophage DSM JG004 was purchased from DSMZ GmbH (Deutsche Sammlung von Mikroorganismen und Zellkulturen, Braunschweig, Germany), and was maintained as a suspension in phosphate-buffered saline $(\mathrm{pH} 7.0)$ at $4{ }^{\circ} \mathrm{C}$ (with a titer of $10^{7}$ plaque-forming units per milliliter of suspension), until use. The (host) bacterial culture used to propagate the phage (P. aeruginosa ATCC 27853) was purchased from ATCC (American Type Culture Collection, Manassas VA, USA), and was revived from a lyophilized state by adding $5 \mathrm{~mL}$ of sterile saline $(9 \% \mathrm{NaCl}, w / w)$ solution, followed by plating in Petri dishes containing solid Nutrient Agar.

\section{Chemicals}

Microbial culture media BHI broth and tryptic soy broth were purchased from Fluka (St. Louis MO, USA) and from Oxoid Ltd. (Basingstoke, Hampshire, England), respectively. Nipagin ${ }^{\circledR} \quad M$ (methyl-parahydroxibenzoate) and glucono- $\delta$-lactone (GDL) were purchased from Sigma-Aldrich (St. Louis MO, USA), dihydrated calcium carbonate $\left(\mathrm{CaCO}_{3} \cdot 2 \mathrm{H}_{2} \mathrm{O}\right)$ was from Panreac (Barcelone, Spain), bacteriological agar for microbiology (code 5126) and low viscosity (300-400 cps) sodium alginate (code 3384) were from VETEC Química Fina Ltda. (Duque de Caxias, Rio de Janeiro RJ, Brazil). Glycerol (anhydrous) was purchased from Fluka (Steinheim, Germany). Filter paper $(0.22 \mu \mathrm{m})$ was purchased from Nalgene (New York, NY, USA), and nonsterile filters $(0.45 \mu \mathrm{m})$ were purchased from Nucleopore (Cambridge, MA, USA). Tap water was purified in a Milli-Q Plus 185 system (Molsheim, France) to a final conductivity of ca. $18.2 \mathrm{M} \Omega \mathrm{cm}^{-1}$. The solvents used were all analytical grade or better, and were used without further purification. 


\section{Analytical Equipment}

All spectrophotometric readings were carried out using disposable 1.5-mL cuvettes (Plastibrand ${ }^{\circledR}$, BRAND GMBH, Wertheim, Germany) in an UV-VIS spectrophotometer (model Gold Spectrumlab 53 from Lengguang Technology Co., Shanghai, China). Morphological and microstructural characterization of the hydrogel matrices via cryoSEM analysis was carried out in a high-resolution scanning electron microscope from JEOL (model JSM 6301F from JEOL, Tokyo, Japan), coupled with a Ion Sputter-Coater JSC1100 (JEOL, Tokyo, Japan), an INCA 350 energy X-ray microanalysis system via energy dispersive spectrometry from Oxford Instrument $\mathrm{GmbH}$ (Wiesbaden, Germany), and a cryo transfer system from Gatan Inc. (model Alto 2500 from Gatan Inc, Pleasanton, CA, USA).

\section{Experimental Procedures}

\section{(Bio)polymer Gelification/Polymerization}

For developing hydrogels with structurally and functionally stabilized phage particles, two biopolymers were evaluated, viz. agar and sodium alginate. As template for the various hydrogel matrices, 12-well cell culture plates were used in all assays, with ca. $2.00 \mathrm{~g}$ of polymeric solution being poured into each well. The hydrogels were produced according to the optimized procedure described by Balcão et al. [5], and yielded perfectly transparent matrices (see Fig. 1).

Agar-Based Hydrogels For preparation of the agar matrices (see Tables 1 and 2), technical agar for microbiology was used with a mass concentration of $1.50 \%(w / w)$. An agar dispersion was prepared by fully dispersing agar in ultrapure water previously heated up to ca. $85^{\circ} \mathrm{C}$, with the aid of a magnetic stirring device, followed by heating up the dispersion thus produced up to $100{ }^{\circ} \mathrm{C}$ for a few seconds to allow complete dissolution of the agar. To preserve the hydrogels from microbial
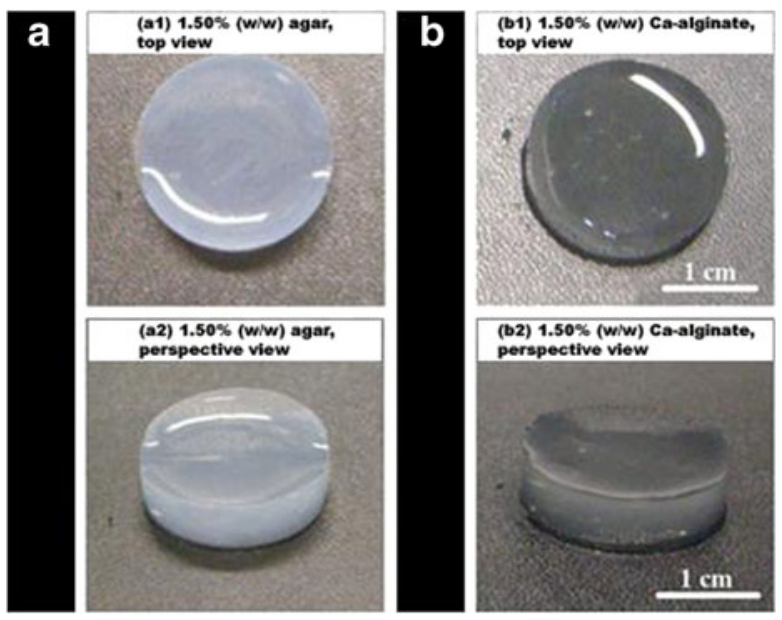

Fig. 1 Macroscopic appearance of the a agar hydrogels obtained with $1.50 \%(w / w)$ biopolymer concentration (top and perspective views) and of the $\mathbf{b}$ calcium alginate hydrogels obtained via the internal gelification method (top and perspective views). All hydrogel matrices depicted in this figure were $5 \mathrm{~mm}$ thick and $20 \mathrm{~mm}$ in diameter 
contaminations, and to extend their useful life, a preservative was added: Nipagin ${ }^{\circledR} \mathrm{M}$, in a concentration of $0.10 \%(w / w)$. This paraben mainly exerts an antifungal action and withstands high temperatures without being degraded. The antifungal agent was added via hot dissolution (ca. $80^{\circ} \mathrm{C}$ ) in the solvent (water). This procedure constituted the first step of the experimental protocol. The resulting clear solution was then poured into each one of the wells of a 12-well cell culture plate, up to $2.0 \mathrm{~g}$ in each well (the 12-well cell culture plate was placed on a semi-analytical scale), allowed to cool down and gelify for ca. $30 \mathrm{~min}$, followed by inversion of the plate and storing at $4{ }^{\circ} \mathrm{C}$ until use was in order.

Sodium Alginate-Based Hydrogels For preparation of the sodium alginate hydrogels $(1.50 \%, w / w)$ a conventional (optimized) approach was used, namely the internal gelification method [5, 19, 20]. To preserve the hydrogels produced from microbial contaminations, and to extend their useful life, a preservative was added: Nipagin ${ }^{\circledR} \mathrm{M}$, in a concentration of $0.10 \%(w / w)$. The antifungal agent was added to the solvent (water) of the formulations. This procedure constituted the first step of the experimental protocol. The polymerization conditions involved calcium carbonate (virtually insoluble in aqueous media) as a source for calcium ions. The process was initiated via preparation (in porcelain mortars) of calcium carbonate (up to a final concentration of $22.5 \mathrm{mM}$ ) and sodium alginate dispersions in ca. $80 \%$ of the total mass of ultrapure water. Occasionally, these dispersions were stirred and allowed to stand by for at least $1 \mathrm{~h}$, so as to allow complete hydration of the sodium alginate. To initiate alginate polymerization, via release of the calcium ions dispersed in the formulation, a fresh aqueous GDL (hydrolysis) solution was added up to a final concentration of $48.0 \mathrm{mM}$. The hydrolysis solution was quickly homogenized with the polymeric dispersion previously prepared, and the mixture thus obtained was transferred immediately into the molds, up to $2.0 \mathrm{~g}$ in each well. The alginate polymerization process was carried out at room temperature, over a time period of $72 \mathrm{~h}$. After this timeframe, the 12well cell culture plates were inverted and the hydrogel matrices produced were maintained at $4{ }^{\circ} \mathrm{C}$ until use was in order.

\section{Incorporation of Phage Particles in the Carbohydrate Hydrogels}

Phage particles were structurally and functionally stabilized within the optimized biopolymeric matrices according to the procedure described by Balcão et al. [5]. Table 1 displays the matrix scheme followed in the preparation of the hydrogels, while Table 2 shows the composition of the final hydrogels produced. Three types of both agar and calcium alginate hydrogels were prepared, according to the matrix scheme displayed in Table 1. For the sake of simplicity, agar and calcium alginate matrices will be referenced from now on, respectively, by AGR and ALG, followed by a set of three digits corresponding to (sequentially) the presence (1) or absence (0) of antifungal agent, phage and bacterial cells.

\section{Evaluation of the Influence of Addition of an Antifungal Agent Upon Bacterial Diffusion in the Hydrogel}

The influence of the antifungal agent upon diffusion of the bacteria in the biopolymeric hydrogels was assessed via comparison of the results obtained for matrices "001" (no antifungal agent added) of each biopolymer with the results observed for their respective matrices with incorporation of the antifungal agent (viz. matrices “101”). 
Table 1 Experimental matrix scheme followed to prepare carbohydrate hydrogels used in bacterial diffusion studies

“+” presence, “-” absence]

\begin{tabular}{llll}
\hline \multirow{2}{*}{ Matrix code } & \multicolumn{2}{l}{ Variable under study } & \\
\cline { 2 - 4 } & Antifungal agent & Bacteriophage & Bacteria \\
\hline 001 & - & - & + \\
010 & - & + & - \\
101 & + & - & + \\
\hline
\end{tabular}

\section{Bacterial Diffusion Studies in the Hydrogels}

Bacterial diffusion assays used the prepared hydrogels (either with or without antifungal agent added), as described previously (see section "(Bio)polymer Gelification/Polymerization" and Balcão et al. [5]), and a P. aeruginosa bacterial suspension.

Preparation of a Suitable Bacterial Host Suspension For preparation of a suitable bacterial suspension of $P$. aeruginosa ATCC 27853, a single collony forming unit was inoculated in a $250 \mathrm{~mL}$ Schott-flask containing $100 \mathrm{~mL}$ of Brain-Heart Infusion broth (BHI broth), and incubated at $37^{\circ} \mathrm{C}$ during $48 \mathrm{~h}$.

Bacterial Diffusion Assays The bacterial diffusion studies were carried out with both carbohydrate hydrogels. They were initiated by flooding the 12 -well cell culture plates (containing the polymerized hydrogels) with the bacterial suspension $(3.50 \mathrm{~mL}$ of bacterial suspension above the hydrogel in each well). Each flooded well was considered as a discrete sampling point in time. At pre-determined time intervals, the bacterial suspension above the hydrogel in the corresponding well was removed with a disposable Pasteur pipette and poured in a plastic cuvette. The absorbance was then read at a wavelength of $610 \mathrm{~nm}$, using plain BHI broth as the blank. The fraction of cells that diffused from the suspension in contact with the surface of the hydrogel into its core was calculated as the difference between the absorbance of the initial bacterial suspension and that corresponding to a sampling time, divided by the absorbance of the initial bacterial suspension.

Structural Microanalysis of the Polymerized Hydrogels via Cryo-SEM, Following Bacterial Diffusion Studies

The biopolymeric hydrogels were analyzed via Cryo-SEM with the objective of both assessing the porous microstructure of the biopolymeric matrices and observe the bacterial cells that difused into their inner core. Following bacterial diffusion studies, each hydrogel was individually sectioned with the aid of a scalpel up to an approximate final dimension of $1 \mathrm{~mm}$ thickness $\times 5 \mathrm{~mm}$ length, and applied in a multiple support. They were deep frozen under vacuum in slush nitrogen at ca. $-210{ }^{\circ} \mathrm{C}$ and transferred, equally under vacuum, into the cryogenic ante-chamber of the scanning electron microscope, stabilized at ca. $-150{ }^{\circ} \mathrm{C}$, where it was fractured. Following fracture, the water present in the samples was removed by sublimation by increasing the temperature up to ca. $-90{ }^{\circ} \mathrm{C}$, during a 3-min period. The temperature of the antechamber was once again lowered to $-150{ }^{\circ} \mathrm{C}$, with the support containing the sample(s) being transferred into the column of the scanning electron microscope, where the fractured samples were sputter coated with an alloy of gold/palladium 


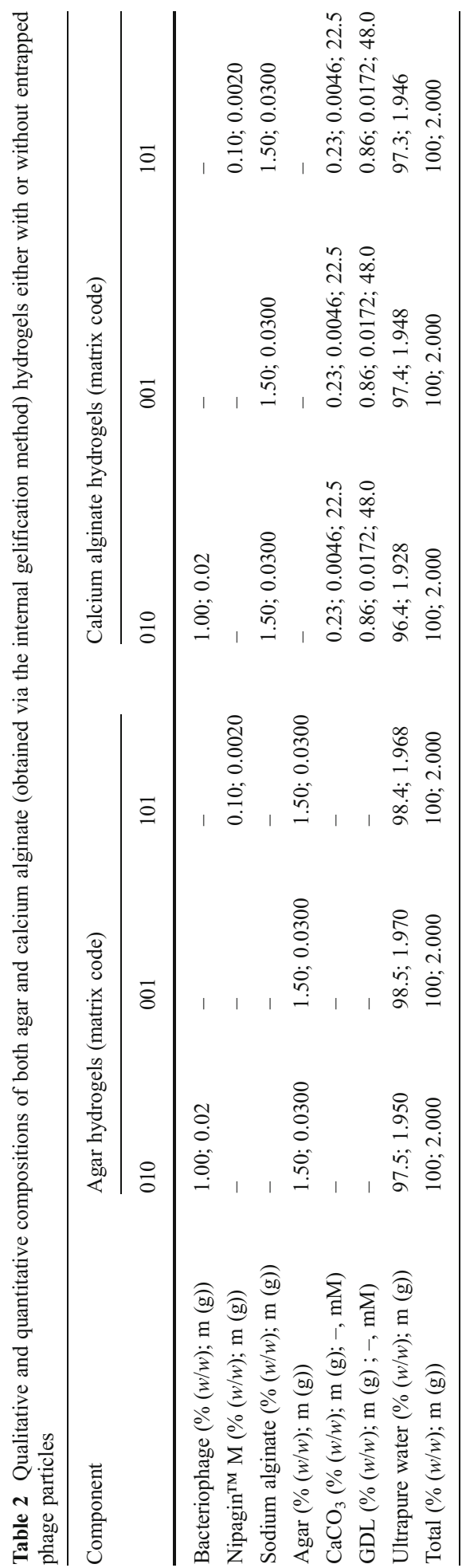


during $45 \mathrm{~s}$, with a current intensity of $12 \mathrm{~mA}$. The sputter-coated samples were observed at several magnifications, and the images were acquired by the INCA ENERGY 350 system (see Fig. 2).

\section{Mathematical Modeling}

The assumptions underlying development of the mathematical model encompass (1) plane geometry, (2) thin hydrogel film, and (3) consideration of unidirectional diffusion (see Fig. 3).

By disregarding the reaction between bacterium and phage, this allows to evaluate the penetration of bacteria on the biopolymeric matrix for the optimization of contact time to achieve bacterial detection. The only driving force for bacterial diffusion considered in this research effort is a cell concentration gradient. A classical diffusion equation based on a material balance for cells in rectangular coordinates can be used to model the diffusion phenomena [21]:

$$
\frac{\partial \mathrm{C}}{\partial \mathrm{t}}=\mathrm{D}_{\text {bact,eff }}\left(\frac{\partial^{2} \mathrm{C}}{\partial \mathrm{x}^{2}}+\frac{\partial^{2} \mathrm{C}}{\partial \mathrm{y}^{2}}+\frac{\partial^{2} \mathrm{C}}{\partial \mathrm{z}^{2}}\right)
$$

where $C$ is the cell concentration, $t$ the exposure time, $D_{\text {bact, eff }}$ the effective diffusion coefficient of bacterial cells in the hydrogel film, and $x, y$, and $z$ represent the rectangular coordinates. For diffusion in one dimension (viz. the $z$-dimension, see Fig. 3), suitable
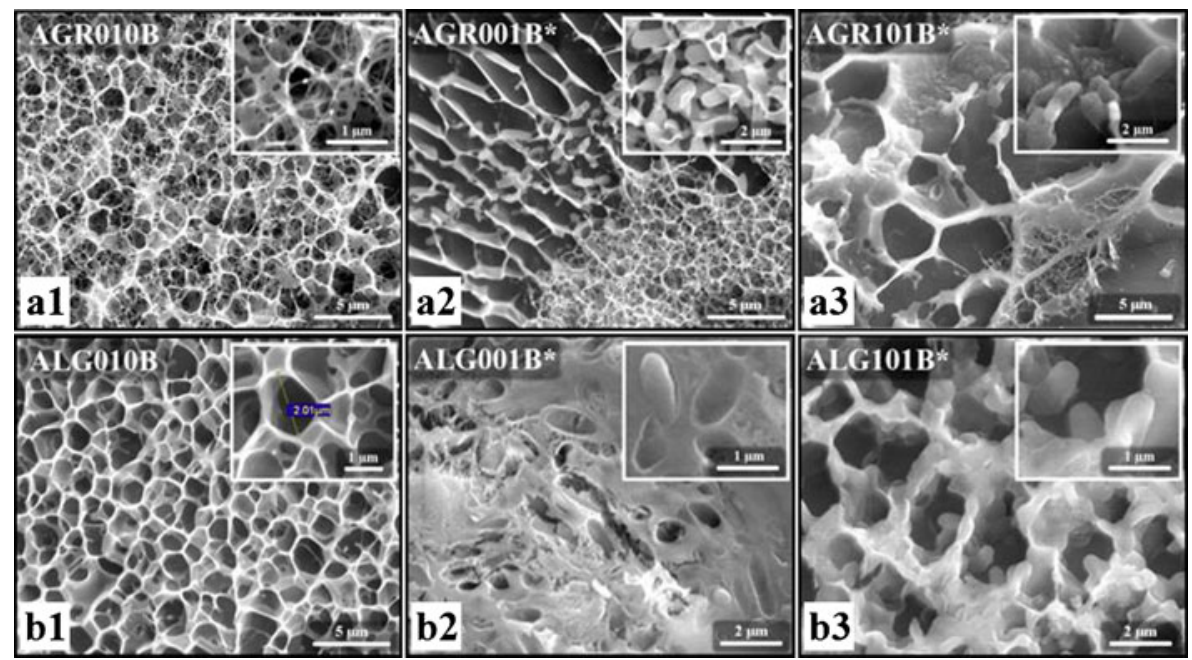

Fig. 2 Cryo-SEM microphotographs of the agar hydrogels (al with stabilized phage particles, without antifungal agent or diffused bacteria; $a 2$ with diffused bacteria, without either phage particles or antifungal agent; $a 3$ without phage particles, with antifungal agent and presence of diffused bacteria) and of the calcium alginate hydrogels ( $b 1$ with stabilized phage particles, without antifungal agent or diffused bacteria; $b 2$ with diffused bacteria, without either phage particles or antifungal agent; $b 3$ without phage particles, with antifungal agent and presence of diffused bacteria), for the different experimental conditions assayed evolving from the experimental design depicted in Table 1. The asterisk in (a2), (a3), (b2), and (b3) indicates the presence of bacterial cells 


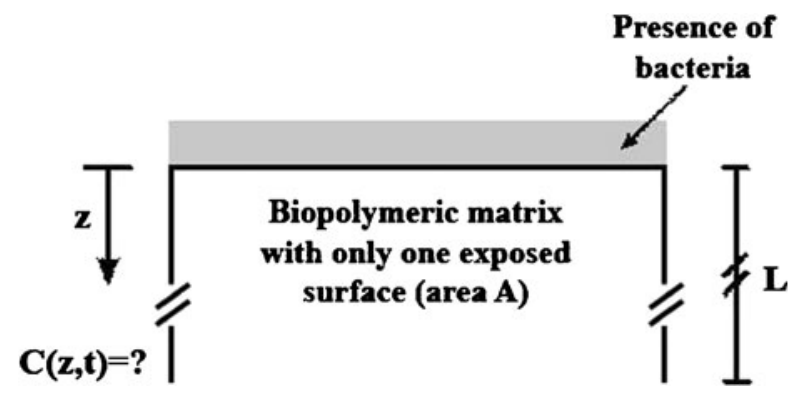

Fig. 3 Dimensions utilized in the modeling rationale for bacterial cell diffusion in the hydrogels and associated experimental setup (where $z$ denotes the longitudinal coordinate, $L$ the total hydrogel thickness, and $C(z, t)$ the bacterial concentration profile)

for a cylindrical matrix with a small cross-sectional area, and considering that bacterial cells only penetrate in the film by diffusion in the direction perpendicular to the contact surface, Eq. (1) reduces to:

$$
\frac{\partial \mathrm{C}}{\partial \mathrm{t}}=\mathrm{D}_{\text {bact,eff }} \frac{\partial^{2} \mathrm{C}}{\partial \mathrm{z}^{2}}
$$

The initial and boundary conditions of the diffusion equation (viz. Eq. (2)) are as follows:

Initial condition: $t=0,0 \leq z \leq L, C=0$ (initially, there are no bacterium cells in the hydrogel matrix);

Boundary condition (1): $t>0, z=0, C=C^{*}$ (bacterial cells placed in contact with the (only) exposed hydrogel surface, at $z$-dimension equal to zero, with a concentration $\left(C^{*}\right)$ maintained constant throughout the experiments timeframe);

Boundary condition (2): $t>0, z=L,\left(\frac{\partial C}{\partial z}\right)_{z=L}=0$ (bacterium cells do not go beyond the limit of the matrix).

Hence, by solving this mathematical model one obtains: (1) C(z,t) (bacterial concentration profile as a function of both z-dimension and time), and (2) M(t) (total amount of bacterium cells incorporated in the matrix by diffusion in a given interval of time). But first, the effective diffusion coefficient of the bacterium ( $\left.D_{\text {bact, eff }}\right)$ in the two carbohydrate hydrogels must be determined, and this will be the subject of the following section.

Determination of the Bacterium Effective Diffusivity

The effective $D_{\text {bact,eff }}$ of the bacteria in each hydrogel was calculated using Eq. (3):

$$
D_{\text {bact,eff }}=\frac{D_{\text {bact,water }} \times \varepsilon \times \delta}{\tau}
$$

where $D_{\text {bact, water }}$ represents the aqueous diffusion coefficient of motile $P$. aeruginosa cells (viz. 2.10 $\times 10^{-9} \mathrm{~m}^{-2} \mathrm{~s}^{-1}$ ) as determined by Kim [11] and Vogt et al. [22], $\varepsilon$ is the porosity of the hydrogel, $\delta$ is the constrictivity factor, and $\tau$ is the tortuosity. 
The estimation of $\varepsilon$ was based on geometric considerations gathered via SEM microphotographs of the hydrogel films (see Fig. 2), and was calculated according to Eq. (4):

$$
\varepsilon=\frac{V_{\text {pores }}}{V_{\text {hydrogel film }}}
$$

The agar hydrogel was found to have a porosity of $95.4 \%$, while that of the calcium alginate hydrogel was $81.5 \%$. The constrictivity factors of the two hydrogels $\left(\delta_{\text {agar hydrogel }}=0.92\right.$; $\delta_{\text {calcium alginate hydrogel }}=0.94$ ) were calculated according to the expression of Currie [23]:

$$
\delta=\frac{\sqrt{(\text { maximum cross-section }) \times(\text { minimum cross-section })}}{\text { mean cross-section }}=\frac{\sqrt{\left(\pi \times r_{p}^{2}\right) \times\left(\pi \times r_{t}^{2}\right)}}{\frac{1}{2} \times\left(\pi \times r_{p}^{2}+\pi \times r_{t}^{2}\right)}
$$

The radiuses of pore $\left(r_{\mathrm{p}}\right)$ and throat $\left(r_{\mathrm{t}}\right)$ were obtained from SEM microphotographs of the two carbohydrate hydrogels (see Fig. 2; agar hydrogel, average pore radius $=0.675 \mu \mathrm{m}$ (average throat radius $=0.450 \mu \mathrm{m}$ ); calcium alginate hydrogel, average pore radius $=1.05 \mu \mathrm{m}$ (average throat radius $=0.775 \mu \mathrm{m}$ )). Regarding the tortuosity, a value of $\tau=\sqrt{3}$ was assumed for both hydrogel films.

Derivation of the Bacterial Concentration Profile in the Hydrogel Matrix as a Function of Both $z$-Dimension and Time

By applying Laplace transforms to Eq. (2), viz.:

$$
L\{C(z, t)\}=\int_{0}^{\infty} e^{-s t} \times C(z, t) \mathrm{d} t=\bar{C}
$$

Thus,

$$
S \times \bar{C}-C(z, 0)=D_{\text {bact,eff }} \frac{d^{2} \bar{C}}{d z^{2}}
$$

Rearranging Eq. (7) one gets:

$$
\frac{d^{2} \bar{C}}{d z^{2}}-\frac{S}{D_{\text {bact, eff }}} \times \bar{C}=0
$$

Equation (8) is a homogeneous ordinary differential equation of 2 nd order with constant coefficients, and its solution becomes:

$$
\bar{C}=A \times e^{\sqrt{\frac{S}{\bar{D}_{\text {bact }, e f f}}} \times z}+B \times e^{-\sqrt{\frac{S}{\bar{D}_{\text {bact }, e f f}}} \times z}
$$

Using the aforementioned boundary conditions, the constants $A$ and $B$ in Eq. (9) can be determined:

$$
\begin{aligned}
& \left(\frac{\partial \bar{C}}{\partial z}\right)_{z=L}=0 \Leftrightarrow \sqrt{\frac{S}{D_{\text {bact,eff }}}} A \times e^{\sqrt{\frac{S}{\overline{b a c t, e f f}}} \times L}-\sqrt{\frac{S}{D_{\text {bact,eff }}}} B \times e^{-\sqrt{\frac{S}{D_{\text {bact,eff }}}} \times L}=0 \Leftrightarrow \\
& \Leftrightarrow A=B \times e^{-2 \sqrt{\frac{S}{D_{\text {bact,eff }}}} \times L}
\end{aligned}
$$


At z $=0, \bar{C}={ }^{C^{*}} /{ }_{S}$, meaning that $C^{*} /{ }_{S}=A+B \Leftrightarrow B={ }^{*} /{ }_{S}-A$, and therefore one gets:

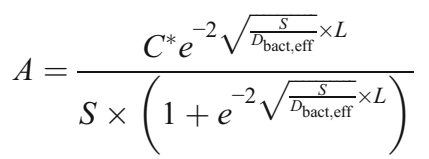

and

$$
B=\frac{C^{*}}{S \times\left(1+e^{-2 \sqrt{\frac{S}{\overline{b a c t, e f f}}} \times L}\right)}
$$

Substituting the expressions for constants $A$ (Eq. (11)) and $B$ (Eq. (12)) in the solution for the homogeneous ordinary differential equation (viz. Eq. (9)), one gets:

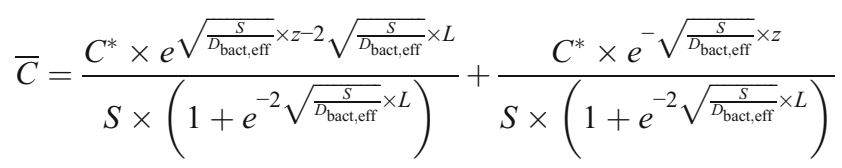

Rearranging Eq. (13) leads to:

$$
\bar{C}=\frac{C^{*}}{S} \times \frac{\cosh \left(\sqrt{\frac{S}{D_{\text {bact,eff }}}} \times(z-L)\right)}{\cosh \left(\sqrt{\frac{S}{D_{\text {bact }, \text { eff }}}} \times L\right)}
$$

The inversion $\left(C(z, t)=L^{-1}\{\bar{C}\}\right)$ can be made using the Heaviside expansion formula (theorem of residues), viz:

$$
L^{-1}\left\{\frac{P(S)}{Q(S)}\right\}=\sum_{k=0}^{\infty} \frac{P\left(S_{k}\right)}{Q^{\prime}\left(S_{k}\right)} \times e^{S_{k} t}
$$

In Eq. (15), the $S_{k}$ are the zeros of $Q(S)$ and $Q^{\prime}(S)$ is the derivative of $Q(S)$. In this particular case,

$$
\begin{aligned}
& P(S)=\cosh \left[\sqrt{\frac{S}{D_{\text {bact,eff }}}} \times(z-L)\right] \quad \text { and } \quad Q(S)=S \times \cosh \left[\sqrt{\frac{S}{D_{\text {bact,eff }}}} \times L\right] \\
& Q^{\prime}(S)=\cosh \left[\sqrt{\frac{S}{D_{\text {bact,eff }}}} \times L\right]+\frac{L}{2} \times \sqrt{\frac{S}{D_{\text {bact,eff }}}} \times \sinh \left(\sqrt{\frac{S}{D_{\text {bact,eff }}}} \times L\right)
\end{aligned}
$$

For calculating the zeros of $Q(S)$, one has $S \times \cosh \left[\sqrt{\frac{S}{D_{\text {bact, fff }}}} \times L\right]=0 \Rightarrow S=0 \vee$ $\cosh \left[\sqrt{\frac{S}{D_{\text {bact,eff }}}} \times L\right]=0$ and thus, using the simplifying substitution (i.e., change of variable) $i \lambda=\sqrt{\frac{S}{D_{\text {bact,eff }}}}$ (where $i=\sqrt{-1}$ ), meaning that $S_{k}=-\lambda_{k}^{2} \times D_{\text {bact,eff, }}$ it follows that 


$$
\begin{aligned}
& \cosh (i \lambda L)=0 \Leftrightarrow \cos (\lambda L)=0 \Leftrightarrow \lambda L=\frac{\pi}{2}+n \pi, n=0,1,2, \ldots \\
& \Leftrightarrow \quad S_{n}=\frac{-(2 n+1)^{2} \pi^{2} D_{\text {bact,eff }}}{4 L^{2}}, \quad n=0,1,2, \ldots
\end{aligned}
$$

Now that the zeros of $Q(S)$ are known, one can calculate the inverse transform. Thus, for $S_{n}=0$, the Heaviside expansion term is given by $\frac{P(0)}{Q^{\prime}(0)}=\frac{\cosh (0)}{\cosh (0)+0}=1$ while for the remaining zeros we have $\cos (\lambda(z-L))=\cos \left[\frac{(2 n+1) \pi}{2 L} \times(z-L)\right]$, and $i \times \sin (\lambda L)=i \times \sin \left(\frac{\pi}{2}+n \pi\right)=i(-1)^{n}, \quad n=0,1,2, \ldots$.

Thus, after performing the necessary algebra, we get

$$
\frac{P\left(S_{k}\right)}{Q^{\prime}\left(S_{k}\right)} \times e^{S_{k} t}=\frac{-4 \times(-1)^{n}}{(2 n+1) \pi} \times \cos \left\{\frac{(2 n+1) \pi}{2 L} \times(z-L)\right\} \times e^{\frac{-(2 n+1)^{2} \pi^{2} D_{\text {bact,eff }}}{4 L^{2}} \times t}
$$

And, finally, the bacterial concentration profile as a function of both $z$-dimension and time is given by the following equation:

$$
C(z, t)=C^{*}\left[1-\frac{4}{\pi} \sum_{n=0}^{\infty} \frac{(-1)^{n}}{2 n+1} \times \cos \left\{\frac{(2 n+1) \pi}{2 L} \times(z-L)\right\} \times e^{\frac{-(2 n+1)^{2} \pi^{2} D_{\text {bact,eff }}}{4 L^{2}} \times t}\right]
$$

Determination of the Total Amount of Bacterium Cells Incorporated in the Hydrogel Matrix by Diffusion in a Given Interval of Time

The amount of bacterium cells that crosses the surface of the hydrogel matrix into its core per unit of time is given by Fick's first law (providing that transport occurs by diffusion only, as is the case in the research effort presented herein):

$$
Q_{(z=0)}=-D_{\text {bact }, \mathrm{eff}} \times A \times\left(\frac{\partial C}{\partial z}\right)_{z=0}
$$

Using Eq. (19) in Eq. (20) one gets:

$$
\left(\frac{\partial C}{\partial z}\right)_{z=0}=-\frac{4}{\pi} \times C^{*} \times \sum_{n=0}^{\infty} \frac{(-1)^{n}}{2 n+1} \times\left(\begin{array}{l}
\frac{-\pi(2 n+1)}{2 L} \times \sin \left[\frac{\pi(2 n+1)}{2 L} \times L\right] \times e^{\frac{-(2 n+1)^{2} \pi^{2} D_{\text {bact. } \mathrm{eff}}}{4 L^{2}} \times t}+ \\
+\left[\cos \left\{\frac{\pi(2 n+1)}{2 L} \times(0-L)\right\}\right] \times 0
\end{array}\right)
$$

Since $\sin \left(\frac{\pi}{2}(2 n+1)\right)=(-1)^{n}, \quad$ one gets $\quad\left(\frac{\partial C}{\partial z}\right)_{z=0}=\frac{2 C^{*}}{L} \times \sum_{n=0}^{\infty} e^{\frac{-(2 n+1)^{2} \pi^{2} D_{\text {bact,eff }}}{4 L^{2}} \times t}$

And thus,

$$
Q_{(z=0)}=-D_{\text {bact }, \text { eff }} \times A \times\left(\frac{2 C^{*}}{L} \times \sum_{n=0}^{\infty} e^{\frac{-(2 n+1)^{2} \pi^{2} D_{\text {bact,eff }}}{4 L^{2}} \times t}\right)
$$

The total amount of bacterial cells incorporated in the hydrogel matrix within the time interval $[0, t]$ is given by the expression: 


$$
M_{t}=\int_{0}^{t} Q_{(z=0)} \mathrm{d} t
$$

Applying the Fundamental Theorem of Calculus, one finally obtains the expression that allows to determine the total amount of bacterial cells incorporated in the hydrogel matrix within a given time interval:

$$
M_{t}=-\frac{8 \times A \times L}{\pi^{2}} \times C^{*} \times \sum_{n=0}^{\infty}\left[\frac{1}{(2 n+1)^{2}} \times\left(1-e^{\frac{-(2 n+1)^{2} \pi^{2} D_{\text {bact,eff }}}{4 L^{2}} \times t}\right)\right]
$$

\section{Results and Discussion}

The hydrogels used in the research effort entertained herein were produced according to the procedure described by Balcão et al. [5] (see Figs. 1 and 2). In the research effort undertaken, the main goal was to find out from a theoretical point of view, which should be the hydrogel characteristics (namely, porosity and thickness) so as to optimize its response as a bacterial biosensing device for P. aeruginosa. For this, a theoretical model was developed and duly validated, allowing prediction of both bacterial concentration profiles (see Eq. (19)) and total fraction of bacteria incorporated in the hydrogels (see Eq. (24)) as a function of both hydrogel porosity, pore constrictivity and hydrogel thickness, assuming as initial estimates for the bacterial diffusivity the values published in the literature for $P$. aeruginosa diffusivity in water, viz. $D_{\text {bact,water }}=2.10 \times$ $10^{-9} \mathrm{~m}^{-2} \mathrm{~s}^{-1}[11,22]$. Agar and alginate hydrogels can be produced with very diverse porosities (ranging from 20 to $97 \%$ ) [24]. According to the theoretical simulations performed, porosity has a major influence on the penetration capability of $P$. aeruginosa cells in the hydrogels. For example, when the porosity increases from $30 \%$ (see Fig. 4a) to $90 \%$ (see Fig. 4d) the value of $c / c^{*}$ at $z=1.5 \mathrm{~mm}$ after an hour exposure, doubles (see Fig. 4). One can also observe that $3 \mathrm{~h}$ of exposure to the bacteria suffice to saturate the more porous hydrogels. The results evolving from mathematical simulations (see Fig. 4a-d) also suggest that obstacle diameter (constrictivity) has an effect on the cell motility and/or penetration, independent of the porosity of the system $[10,25,26]$, which is more pronounced for intermediate levels of hydrogel saturation. From a close inspection of Fig. 4 one can see that for higher porosity values the constrictivity factor has a more pronounced effect on the (normalized) bacterial concentration profiles at intermediate contact times between hydrogel surface and bacterial suspension (see e.g., the curves for $10 \mathrm{~min}, 30 \mathrm{~min}$, and $1 \mathrm{~h}$, in Fig. 4a-d).

Sahimi and Jue [27] used a similar approach to simulate macromolecular diffusion in a disordered porous medium, corresponding to the Brownian motion of macromolecules found in a real system. These authors found a sharp dependence of the effective diffusion coefficient on the mean pore diameter of the medium. It is therefore possible that the average effective random motility of the bacterial cells is a function of the pore morphology (dictated by its constrictivity). However, bacterial diffusion in a porous medium differs in several ways from the system modeled by Sahimi and Jue [27] as those researchers considered bulk diffusion where the molecular mean free path is small compared with the mean pore diameter. On the other hand, if one considers the opposite situation, i.e., Knudsen diffusion (described by the Einstein model), diffusion occurs when the natural molecular mean free 

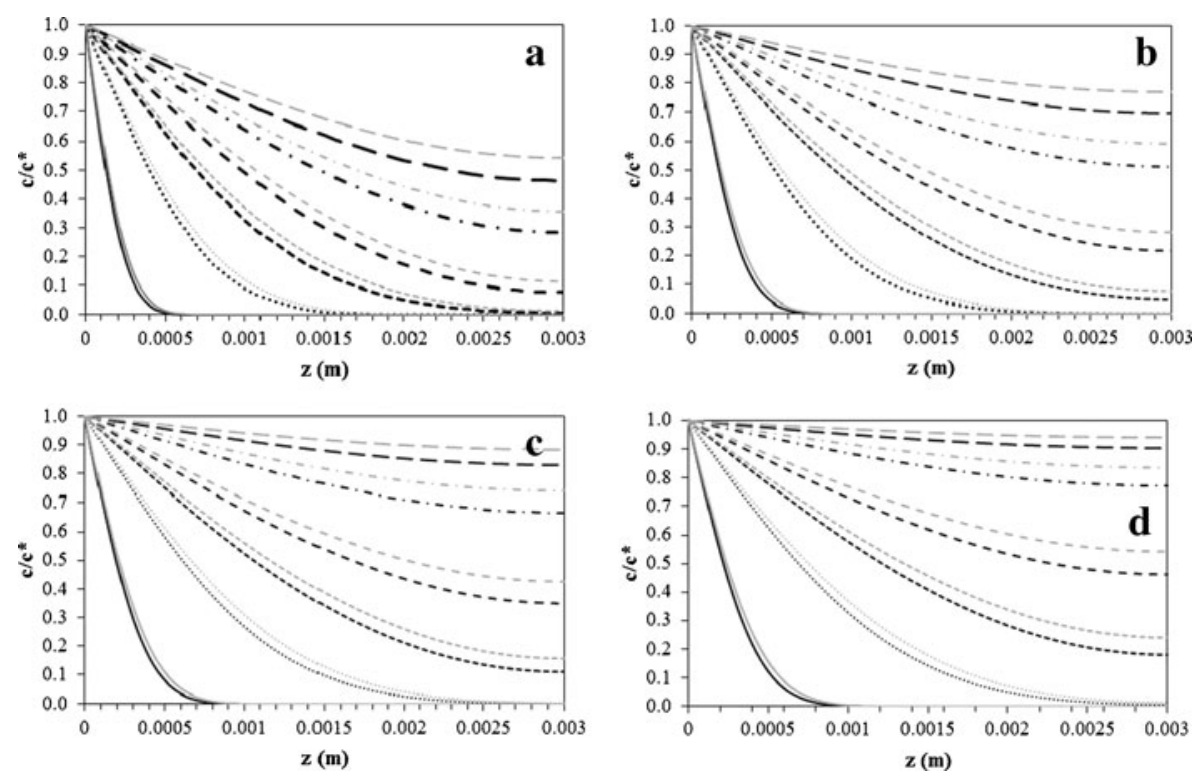

Fig. 4 Results evolving from mathematical simulations for the (normalized) bacterial concentration profiles as a function of hydrogel $z$-coordinate, for different contact times between hydrogel surface and bacterial suspension, for different porosities $(\varepsilon)$ and constrictivity factors $(\delta ; \mathbf{a} \varepsilon=0.3, \delta=0.8$ (black lines), $\delta=0.95$ (grey lines); $\mathbf{b} \varepsilon=0.5, \delta=0.8$ (black lines), $\delta=0.95$ (grey lines); $\mathbf{c} \varepsilon=0.7, \delta=0.8$ (black lines), $\delta=0.95$ (grey lines); d

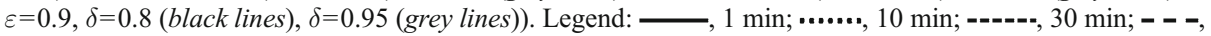
$1 \mathrm{hr} ;-\cdot-\cdot, 2 \mathrm{hr} ;--, 3 \mathrm{hr}$

path is much greater than the mean pore diameter $[10,28]$. For bacterial diffusion in a porous matrix such as biopolymeric hydrogels, the process lies in the transition between these two extremes (viz. bulk diffusion vs. Knudsen diffusion), because the bacterial mean free path is of the same order as the magnitude of the mean pore diameter. This was the case with the polymeric hydrogels assayed in the research effort described herein. There are two further differences between Brownian motion of (macro)molecules and bacterial motility [29]. Firstly, bacteria such as $P$. aeruginosa have a small bias to persist in their direction of motion after tumbling [10], whereas in the Brownian motion of (macro)molecules the direction after collisions has a uniform random turn. Secondly, the change in direction made by the cells takes a finite time, whereas in Brownian motion a change in direction is considered to be instantaneous. Thus, the extrapolation of the results of Sahimi and Jue [27] for (macro)molecules, to the behavior of bacterial cells, is not straightforward. A molecule, or a much larger Brownian particle, is in thermal equilibrium with the medium in which it is immersed, whereas self-propelled bacteria (such as P. aeruginosa) have a much greater average speed of motion than that caused by spontaneous fluctuation within the medium and are not in thermal equilibrium with the medium [29]. To focus purely on bacterial diffusion, the experimental setup was designed so as to keep bacterial growth to a minimum (all experiment timeframes were limited to $180 \mathrm{~min}$, since the media in which the bacteria swam contained a carbon source). In Fig. 5, one can see the (simulated) total fraction of bacteria incorporated in the hydrogels as a function of both hydrogel porosity $(\varepsilon)$ and constrictivity $(\delta)$ factors. The experimental results obtained (see Fig. 7) confirm the trends that were inferred from the analysis of the simulated concentration profiles (see Fig. 4). Once again, one can notice that porosity has a marked effect on the ability of 


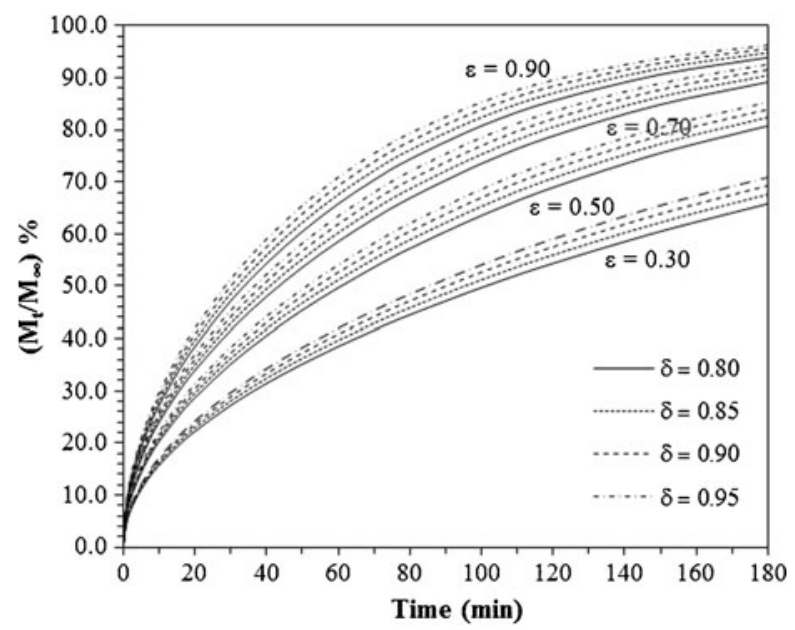

Fig. 5 Results evolving from mathematical simulations for the total bacterial amount incorporated in the biopolymer hydrogel as a function of contact time between hydrogel surface and bacterial suspension, for different porosities $(\varepsilon)$ and constrictivity factors $(\delta) . M_{t}$ and $M_{\infty}$ represent the amounts of diffusing bacteria in the receiving compartment at time $t$ and at equilibrium between the hydrogel and the suspension, respectively

bacteria to penetrate in the hydrogel. The pore constrictivity is not so determinant, yet when it varies from 0.80 to 0.95 an increase of $6 \%$ in the fraction of bacteria incorporated can be noticed (see Fig. 5). As from the analysis of the theoretical concentration profiles (see Fig. 4), it is noted again that the effect of the constrictivity factor is more pronounced at intermediate levels of saturation of the hydrogel.

To confirm the validity of the mathematical model developed, experimental trials were performed where only one of the surfaces of the hydrogels under study was exposed to a bacterial suspension (see Fig. 3), and the time evolution of the absorbance of the supernatant suspension was followed. Our experimental setup was similar to that used by Holte et al. [26]. The experimental results gathered with standard deviation bars (each point is the simple average of 6 determinations) together with the nonlinear fitting of Eq. (24) for the total fraction of bacteria incorporated in the hydrogel are displayed in Fig. 6a for the agar hydrogel and in Fig. $6 \mathrm{~b}$ for the calcium alginate hydrogel. As can be seen from inspection of Fig. 6a-b, the theoretical model postulated seems to accurately describe the experimental data evolving from both agar hydrogel and calcium alginate hydrogel bacterial diffusion trials.

From the nonlinear fittings of the model (viz. Eq. (24)) to the experimental data (see Fig. 6), one obtained the effective bacterial ( $P$. aeruginosa) diffusion coefficients in the agar hydrogel (viz. $D_{\text {bact, eff }}=2.456 \times 10^{-11} \mathrm{~m}^{-2} \mathrm{~s}^{-1}$, see Fig. 6a) and in the calcium alginate hydrogel (viz. $D_{\text {bact, eff }}=1.290 \times 10^{-10} \mathrm{~m}^{-2} \mathrm{~s}^{-1}$, see Fig. 6b). Being these effective bacterial diffusion coefficients the real diffusion coefficients of $P$. aeruginosa in the agar and calcium alginate hydrogels, then the (predicted) time evolution of concentration profiles along the $z$ coordinate in the agar hydrogel (see Fig. 3) are the ones displayed in Fig. 7a while those for the calcium alginate hydrogel are the ones displayed in Fig. 7b. From a close inspection of Fig. 7a, one concludes that it takes about $5 \mathrm{hr}$ for $P$. aeruginosa cells to penetrate $3 \mathrm{~mm}$ deep into the agar hydrogel core, while this time is reduced to only $1 \mathrm{hr}$ in the case of the calcium alginate hydrogel (see Fig. 7b). Based on these results, it can be inferred that a detection device using the alginate hydrogel will respond more rapidly. Moreover, for effective 
Fig. 6 Nonlinear fitting of the mathematical model that gives the total amount of bacterial cells incorporated in the hydrogel matrix within a given time interval to the experimental data gathered for the a agar hydrogel as a function of contact time between agar hydrogel surface and bacterial suspension, using agar hydrogel determined porosity $(95.4 \%)$ and constrictivity (0.92) factors and $\mathbf{b}$ calcium alginate hydrogel as a function of contact time between calcium alginate hydrogel surface and bacterial suspension, using calcium alginate hydrogel determined porosity $(81.5 \%)$ and constrictivity (0.94) factors. Each experimental data point is the average of 6 determinations, and error bars represent standard deviations arising from the 6 measures for each experimental data point. (Legend: [ Experimental data;-----Theoretical fit)
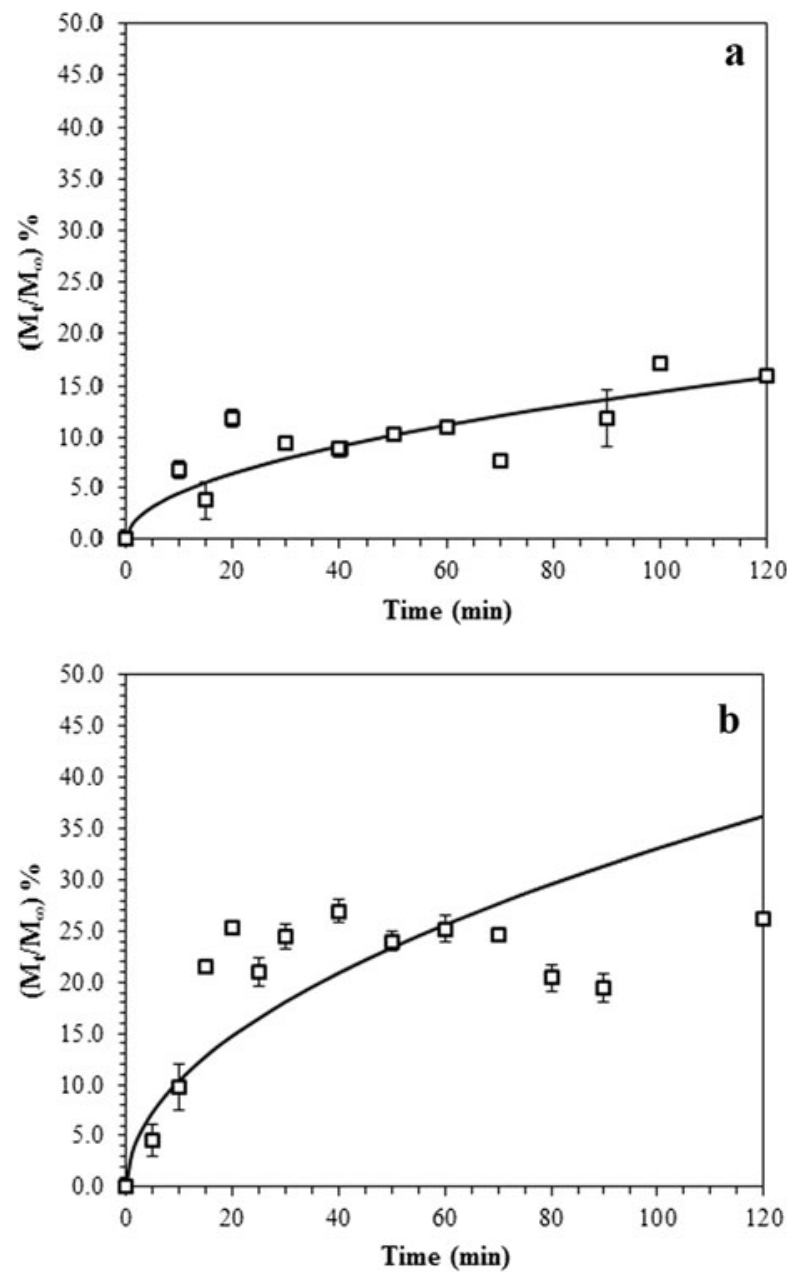

bacterial detection to be achieved in a shorter timeframe the agar hydrogel thickness must be at least $3 \mathrm{~mm}$.

Additionally, as time elapses, imprisonment of bacterial cells that penetrated deep into the hydrogel core leads to thermodynamic stability, which can be correlated with a change in the thermodynamic conditions of the microenvironment surrounding each bacterial cell as the movements of (aqueous) solvent molecules in their microneighborhood become seriously reduced by the effect of being contained within the hydrogels' core. The result is that the bacterial entity's rotational, translational and vibrational viscosity becomes enhanced, leading to a more rigid 3D architecture with concomitant decrease of entropy [30]. The smaller pore size and throat diameter increased the bacterial cell's rotational, translational and vibrational viscosity promoted by such narrower pores, and this may be the reason why the $P$. aeruginosa cells did not penetrate so deep into the agar hydrogel (average pore radius $=0.675 \mu \mathrm{m}$, average throat radius $=0.450 \mu \mathrm{m}$ ). On the contrary, the calcium alginate hydrogel possessed pores with both larger diameters and larger throat diameters (average pore radius $=1.05 \mu \mathrm{m}$, average throat radius $=0.775 \mu \mathrm{m}$ ), which may have facilitated a quicker and deeper penetration of the bacterial cells into its core. According to Duffy et al. [10], an increase in path length increases the tortuosity, which counteracts the directed 

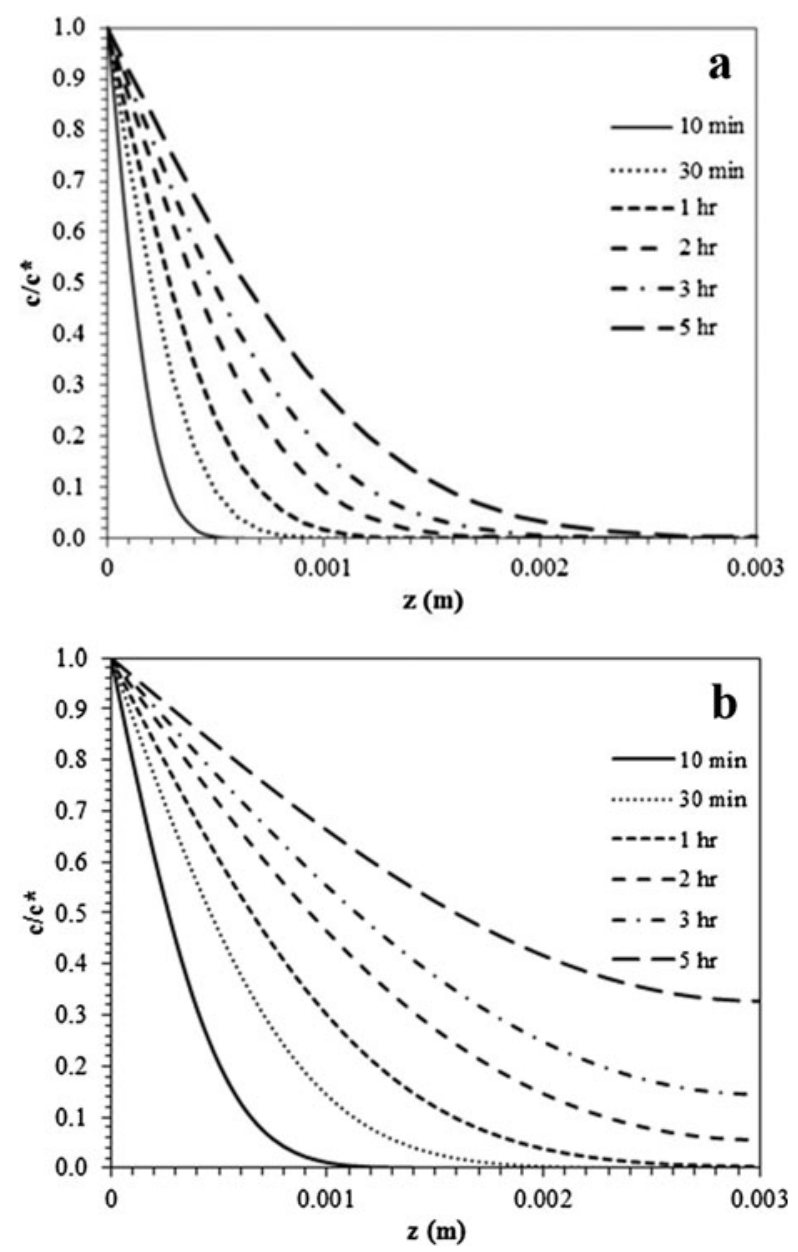

Fig. 7 Results evolving from mathematical simulations for the (normalized) bacterial concentration profiles a as a function of agar hydrogel $z$-coordinate, for different contact times between agar hydrogel surface and bacterial suspension, using agar hydrogel-determined porosity $(95.4 \%)$ and constrictivity factor $(0.92)$, for the effective bacterial diffusivity in the agar hydrogel as calculated from the nonlinear fitting performed to the experimental data, and $\mathbf{b}$ as a function of calcium alginate hydrogel $z$-coordinate, for different contact times between calcium alginate hydrogel surface and bacterial suspension, using calcium alginate hydrogel-determined porosity (81.5\%) and constrictivity factor (0.94), for the effective bacterial diffusivity in the calcium alginate hydrogel as calculated from the nonlinear fitting performed to the experimental data (see Fig. 6)

motion of bacterial cells. This suggests that, within the confines of the experimental situation presented in this research effort, simulating natural situations, it is likely that increased local viscosity and presence of fiber obstacles within the pores influence the bacterial cell migration significantly on a local level. We were interested in studying the effect of pore morphology upon bacterial migration. Transport in a porous matrix such as the carbohydrate hydrogels produced is hindered primarily by the volume fraction of obstructions. However, different media can inhibit transport to varying degrees if there are differences in path space available to the bacterial cells. The complexity of individual paths available to the cells can vary depending on the morphology of the hydrogel matrix. Such an effect of morphology upon diffusion is commonly referred to as tortuosity. In practice, however, this term often includes a number of effects including path 
tortuosity, hydrodynamic effects, chemical interactions, and surface interactions, and therefore we intended to characterize geometric aspects associated with the pore diameter and throat diameter relative to the bacterial path length and the tortuous nature of the pore path within the hydrogel porous matrix. Before separating out the effects of morphology on the tortuosity, one must consider the mechanism of cell diffusion within the pore space of the hydrogel matrix. For molecular diffusion, there are two dominant mechanisms, one depending primarily on molecular collisions and another depending primarily on molecule-surface collisions [31]. These mechanisms are referred to as bulk and Knudsen diffusion, respectively. The situation of interest here is when a combination of the two mechanisms operate, which is referred to as a transition regime. As obstacle size decreases, the tortuosity associated with the porous matrix increases. For smaller obstacle diameters, this effect is significant and is primarily due to the geometry of the hydrogel matrix. The dominant aspects of this are the ratio of mean free path of the bacteria to pore diameter. Surface interactions between bacteria and obstacles (viz. pore walls) can be expected to reduce random motility and, thus, increase tortuosity. The extent of this effect depends on the number of bacteriaobstacle collisions. This in turn will depend on the obstacle surface area to pore volume ratio. A better understanding of the role of bacteria-obstacle surface interactions and the importance of chemotaxis for bacterial motility in hydrogel porous media is therefore needed. In a porous matrix, such as the hydrogels tested, the cells might be considered as macromolecules and their diffusion behavior may be similar to molecular diffusion [32]. The pathogenic bacteria $P$. aeruginosa produces a well-known extracellular polymeric substance, i.e., alginate [12, 22], when cell densities are high enough (a process known as quorum sensing), and because a highly mucoid strain was used (viz. ATCC 27853) experimental variations in absorbance were sometimes obtained due to the large amount of exopolysaccharide produced. During the carbohydrate polymerization process, hyperentanglements will form within the core of the hydrogel matrix resulting in a further decrease in bacterial mobility and penetration [33]. It is believed that the formed hyper-entanglements on the core of the hydrogels, associated to increased local viscosity, rapidly reduce bacteria mobility and prevent a homogeneous dispersion in the hydrogel [33]. In calcium alginate gels, the diffusion coefficient obtained by Liu et al. [32] for Cellulosimicrobium cellulans GS6 was equal to 2.7× $10^{-10} \mathrm{~m}^{-2} \mathrm{~s}^{-1}$, a value that is in close agreement with the (real) effective diffusivity determined by us for $P$. aeruginosa in calcium alginate hydrogel (viz. $1.290 \times 10^{-10} \mathrm{~m}^{-2} \mathrm{~s}^{-1}$ ) and only one order of magnitude above our value for the effective diffusion coefficient of $P$. aeruginosa cells in the agar hydrogel (viz. $2.456 \times 10^{-11} \mathrm{~m}^{-2} \mathrm{~s}^{-1}$ ). Wu et al. [34] found that the diffusion coefficient increased with increasing cell density, a phenomenon that can be attributed to the hydrodynamic disturbances caused by neighboring bacteria. Hydrodynamic interactions between pairs of swimming bacteria can be important when the distance between them is less than a cell length (including flagella) [35]. The description of the diffusion of an entity in a continuous medium is usually based on Fick's law, which defines the diffusion coefficient of the solute in the media. Combined with conservation of matter, Fick's law leads to the diffusion equation, whose solution yields the usual expression for the mean-square displacement of a diffusing particle in three dimensions [36], which is characteristic of a simple diffusion process. The dependence of the diffusion coefficient on the hydrodynamic radius of the diffusing particle and on the solvent viscosity is captured in the Stokes-Einstein equation [37]. However, whereas Fick's law is an established phenomenological law for diffusion in isotropic fluids, there is no physical reason why it should always apply to more complex systems such as porous hydrogels. The process of transport of substrates to the (diffusing) microbial cells may take place not only by passive molecular diffusion but also by advection caused either by the movement of the fluid relative to the microorganism or by their active swimming. The ratio of transport by

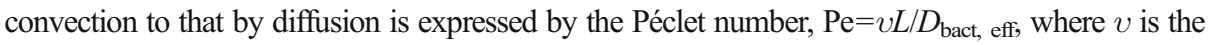
relative velocity between the organism and the fluid, $D_{\text {bact, eff }}$ is the effective diffusion coefficient, and $L$ is the characteristic length of the organism (or rather the thickness of its diffusive boundary 
layer, which for small organisms is of similar magnitude) [38]. When Pe»1, fluid flow or swimming strongly enhance substrate availability relative to diffusion alone. However, Pe 1 for normal motile bacteria, which means that the bacteria cannot gain more substrate by swimming around as compared with passively waiting for the substrate to reach them by diffusion [38]. With diffusion coefficients typically around $10^{-9} \mathrm{~m}^{2} / \mathrm{s}$ for dissolved organic substrates, organisms must be larger than about $10 \mu \mathrm{m}$ before they gain more substrate by swimming. This was clearly not the case in our experimental assays as $P$. aeruginosa cells typically have much smaller dimensions $(0.6 \times 1.5 \mu \mathrm{m})$. According to the Stokes-Einstein relation, a 1-mm-sized particle should exhibit a diffusion coefficient of ca. $0.5 \mathrm{~mm}^{2} / \mathrm{s}$ in water [39]. Holte et al. [26] determined effective diffusion coefficients of diffusion probes in the gels from the concentration profiles of the probes in the solutions connected to the gels. Similarly to our model, $M_{t}$ and $M_{\infty}$ were amounts of diffusing solute in the receiving compartment at time $t$ and at equilibrium between the gel and the solution, respectively. The diffusion of model substances in calcium alginate gel samples was studied by Holte et al. [26]. By comparing the diffusional behaviour of low molecular weight quinine sulphate and high molecular weight dextran, those authors suggested that the two substances diffuse through the gel sample by different mechanisms. Quinine sulphate would diffuse rather freely through pores in the gel, whereas dextran diffusion would be dependent on the mobility of the gelling alginate molecules. Thus, increasing the amount of gelling calcium ions in the alginate gel would retard dextran diffusion, whereas quinine diffusion would be faster. The experimental data by Holte et al. [26] suggest that calcium alginate gels are suitable not only for encapsulating large drug molecules like proteins, but also for controlling the release of such compounds, e.g., from a pharmaceutical formulation. P. aeruginosa swarming is very complex and involves sophisticated quorum sensing schemes and cell and (micro)environment interactions [13]. During the course of swarming, cells extract extracellular "wetting" liquid from the surface of the hydrogel. The motion of the individual flagellated $P$. aeruginosa cells as well as the swarm expansion is then aided by changes in physical properties within and on the surface of the newly developed thin liquid film. P. aeruginosa is a common Gram-negative bacterium. It is one of many bacteria that utilize cell-cell signaling mechanisms (quorum sensing), to coordinate gene expression. Quorum sensing bacteria use diffusible or excreted chemical signals as cues to coordinate gene expression among bacterial communities for a variety of different activities including (but not limited to): luminescence, DNA uptake, sporulation, antibiotic production, and in the case of $P$. aeruginosa, virulence. Swarming motility of $P$. aeruginosa has also been shown to be greatly influenced by quorum sensing via the production of rhamnolipid (a biosurfactant) at high cell density as a quorum sensing response. $P$. aeruginosa uses its single polar flagellum that operates as a rear propulsion engine when swarming, a behavior similar to that of Escherichia coli [40]. Biosensors based on microorganisms immobilized in calcium alginate and agarose displayed almost the same sensitivities and linear ranges as their suspensions. The use of gels instead of intact cell suspension facilitates, however, handling and hence, is desirable when designing an integrated bioanalytical system of practical use [41]. In our case, the hydrogels optimized and duly characterized are intended for entrapping phage particles and exhibit chromogenic characteristics upon penetration of bacterial cells and reaction with the stabilized phage particles, whereas bacteria is supposedly present in fluids (either a biological fluid such as saliva or sputum or air) contacting a single surface of the hydrogel.

\section{Conclusions}

The research effort presented herein is the second part of a published paper and constitutes the prologue of a forthcoming third paper. The research entailed had as its main goal the development and implementation of a suitable mathematical model that describes bacteria 
diffusion into carbohydrate hydrogels containing fully stabilized (both structurally and functionally) bacteriophage particles, aiming at optimizing the hydrogel thickness that gives the fastest chromogenic bacterial ( $P$. aeruginosa) biosensing response. The mathematical model developed was found to accurately describe bacterial diffusion into the core of carbohydrate hydrogels, taking into consideration variables such as tortuosity, porosity, and constrictivity factors of the biopolymeric matrices. Additionally, the mathematical model developed allowed determination of the real (effective) diffusion coefficient for $P$. aeruginosa in both agar and calcium alginate based hydrogels. The mathematical simulations performed were consistent with experimental data gathered and clearly demonstrated the influence of porosity and constrictivity factor upon bacterium diffusion into the hydrogel core, allowing to conclude that hydrogels thinner than $3 \mathrm{~mm}$ may be utilized for attaining bacterial biosensing in less than $5 \mathrm{~h}$ of contact between hydrogel surface and a biological fluid. Analysis of the hydrogels via Cryo-SEM, following bacterial diffusion experiments, revealed the existence of a porous microstructure with intricate characteristics appropriate for protection of the phage particles, without restraining their easy access to the specific bacterial host so as to promote lysis. Full structural and functional stabilization of the phage particles can also be correlated with a change in the thermodynamical conditions of the microenvironment surrounding each phage particle, since the movements of (aqueous) solvent molecules within their immediate microneighborhood were seriously impaired by the gellification effect of the polymeric matrix, which is in clear agreement with the stabilization of protein molecules described in the scientific literature $[5,30]$. Inclusion of a chromogenic mechanism in the selected hydrogels for detection of intracellular bacterial components released upon phage-based bacterial lysis, aiming at development of an innovative (disposable) pathogenic bacteria biosensing device, will be the subject of a forthcoming (part III) manuscript.

Acknowledgments Financial support to Victor M. Balcão, via an Invited Research Scientist fellowship (FAPESP Ref. No. 2011/51077-8) by Fundação de Amparo à Pesquisa do Estado de São Paulo (FAPESP, São Paulo, Brazil), is hereby gratefully acknowledged.

\section{References}

1. Nicolle, L. E. (2002). In L. Breslow (Ed.), Encyclopedia of public health, vol 3 (pp. 828-830). New York: Macmillan Reference.

2. Davey, P., Brown, E., Fenelon, L., Finch, R., Gould, I., Holmes, A., et al. (2006). Emerging Infectious Diseases, 12, 211-216.

3. Klevens, R. M., Edwards, J. R., Richards, C. L., Jr., Horan, T. C., Gaynes, R. P., Pollock, D. A., et al. (2007). Public Health Reports, 122, 160-166.

4. Flickinger, S. T., Copeland, M. F., Downes, E. M., Braasch, A. T., Tuson, H. H., Eun, Y.-J., et al. (2011). Journal of the American Chemical Society, 133, 5966-5975.

5. Balcão, V. M., Moreira, A. R., Moutinho, C. G., Chaud, M. V., Tubino, M., \& Vila, M. M. (2013). Enzyme and Microbial Technology, 53, 55-69.

6. Giamarellou, H. (2002). Journal of Antimicrobial Chemotherapy, 49, 229-233.

7. Kerr, K. G., \& Snelling, A. M. (2009). Journal of Hospital Infection, 73, 338-344.

8. Caselli, D., Cesaro, S., Ziino, O., Zanazzo, G., Manicone, R., Livadiotti, S., et al. (2010). Haematologica, $95,1612-1615$.

9. Neves, M. T., Lorenzo, M. E. P., Almeida, R. A. M. B., \& Fortaleza, C. M. C. B. (2010). Revista da Sociedade Brasileira de Medicina Tropical, 43, 629-632.

10. Duffy, K. J., Cummings, P. T., \& Ford, R. M. (1995). Biophysical Journal, 68, 800-806.

11. Kim, Y.-C. (1996). Korean Journal of Chemical Engineering, 13, 282-287. 
12. Dockery, J. D., \& Keener, J. P. (2001). Bulletin of Mathematical Biology, 63, 95-116.

13. Du, H., Xu, Z., Shrout, J. D., \& Alber, M. (2011). Mathematical Models and Methods Applied Sciences, 21, 939-954.

14. Omidian, H., \& Park, K. (2008). Journal of Drug Delivery Science and Technology, 18, 83-93.

15. Chandra, R., \& Rustgi, R. (1998). Progress in Polymer Science, 23, 1273-1335.

16. Pal, K., Banthia, A. K., \& Majumdar, D. K. (2009). Designed Monomers and Polymers, 12, $197-220$.

17. Annabi, N., Nichol, J. W., Zhong, X., Ji, C., Koshy, S., Khademhosseini, A., et al. (2010). Tissue Engineering Part B, 16, 371-383.

18. Lieleg, O., \& Ribbeck, K. (2011). Trends in Cell Biology, 21, 543-551.

19. Draget, K. I., Moe, S. T., Skjak-Bræk, G., \& Smidsrod, O. (2006). In A. M. Stephen, G. O. Phillips, \& P. A. Williams (Eds.), Food polysaccharides and their applications (2nd ed., pp. 289-334). New York: Taylor \& Francis.

20. Donati, I., \& Paoletti, S. (2009). In B. H. A. Rehm (Ed.), Alginates: biology and applications (pp. 1-53). Münster: Springer.

21. Fahien, R. (1983). Fundamentals of transport phenomena. McGraw-Hill, New York.

22. Vogt, M., Flemming, H.-C., \& Veeman, W. S. (2000). Journal of Biotechnology, 77, 137-146.

23. Currie, J. A. (1960). British Journal of Applied Physics, 11, 318-324.

24. Nussinovitch, A. (2010). In: Nussinovitch, A (ed) Polymer macro- and micro-gel beads: fundamentals and applications, Ch. 2. Springer, New York. pp. 27-52.

25. Barton, J.W. (1994). Ph.D. thesis, University of Virginia, Charlottesville, VA, USA.

26. Holte, Ø., Tønnesen, H. H., \& Karlsen, J. (2006). Pharmazie, 61, 30-34.

27. Sahimi, M., \& Jue, V. L. (1989). Physical Review Letters, 62, 629-632.

28. Malek, K., \& Coppens, M. O. (2003). Journal of Chemical Physics, 119, 2801-2811.

29. Thonemann, P. C., \& Evans, C. J. (1976). Journal of General Microbiology, 92, 25-31.

30. Balcão, V. M., Costa, C. I., Matos, C. M., Moutinho, C. G., Amorim, M., Pintado, M. E., et al. (2013). Food Hydrocolloids, 32, 425-431.

31. Reyes, S. C., \& Iglesia, E. (1991). Journal of Catalysis, 129, 457-472.

32. Liu, C.-H., Wu, J.-Y., \& Chang, J.-S. (2008). Bioresource Technology, 99, 1904-1910.

33. Burke, M. D., Park, J. O., Srinivasarao, M., \& Khan, S. A. (2005). Journal of Controlled Release, 104, $141-153$.

34. Wu, M., Roberts, J. W., Kim, S., Koch, D. L., \& DeLisa, M. P. (2006). Applied and Environmental Microbiology, 72, 4987-4994.

35. Tindall, M. J., Maini, P. K., Porter, S. L., \& Armitage, J. P. (2008). Bulletin of Mathematical Biology, 70, 1570-1607.

36. Banks, D. S., \& Fradin, C. (2005). Biophysical Journal, 89, 2960-2971.

37. Butenko, A. V., Mogilko, E., Amitai, L., Pokroy, B., \& Sloutskin, E. (2012). Langmuir, 28, 12941-12947.

38. Schulz, H. N., \& Jørgensen, B. B. (2001). Annual Review of Microbiology, 55, 105-137.

39. Lieleg, O., Vladescu, I., \& Ribbeck, K. (2010). Biophysical Journal, 98, 1782-1789.

40. Wolfe, A. J., \& Berg, H. C. (1989). Proceedings of the National Academy of Sciences of the United States of America, 86, 6973-6977.

41. Leth, S., Maltoni, S., Simkus, R., Mattiasson, B., Corbisier, P., Klimant, I., et al. (2002). Electroanalysis, $14,35-42$. 